\title{
STATISTICAL PROCESS CONTROL APPLIED TO MONITOR LOSSES IN THE MECHANIZED SUGARCANE HARVESTING
}

\author{
Carla S. S. Paixão ${ }^{1^{*}}$, Murilo A. Voltarelli², Rouverson P. da Silva ${ }^{3}$, \\ Mateus A. de P. Borba ${ }^{3}$, Luma S. Torres ${ }^{3}$ \\ ${ }^{1 *}$ Corresponding author. Centro Universitário FACENS/ Sorocaba - SP, Brasil. \\ E-mail: carla.voltarelli@facens.br | ORCID ID: https://orcid.org/0000-0001-7280-1219
}

\section{KEYWORDS}

harvester, visible losses, Saccharum spp.

\begin{abstract}
The mechanized sugarcane harvesting process is considered one of the major economic bottlenecks, with low operational efficiency and, mainly, high losses of stalks left in the field. In order to minimize these problems and assist in the improvement of processes, this study aimed to evaluate the losses in the mechanized sugarcane harvesting using statistical process control. The experimental design was completely randomized, based on the methodology of statistical process control with samples collected on five work fronts during the daytime and nighttime operation. The experiment was carried out in an agricultural area of a sugarcane mill in the municipality of Ribeirão Preto, SP, Brazil, on five sugarcane harvest fronts. Losses were measured using a $3.0 \times 3.33-\mathrm{m}$ frame, being divided into stump, loose piece + fixed piece, whole sugarcane, fragment, and total losses for each harvest front. The data were grouped into 50 weeks over the sugarcane-growing season, and statistical analyses were performed using the Minitab $16^{\circledR}$ software. Losses of loose piece + fixed piece were higher than the losses of stump, whole sugarcane, and fragment. The total losses showed higher and lower losses for the fronts F5 and F4, respectively, compared to the others.
\end{abstract}

\section{INTRODUCTION}

Among the sugarcane agricultural activities is the mechanized harvesting process, which involves the cutting, loading, and transportation and are considered of greatest economic importance. According to Oliveira et al. (2012), these operations represent about $30 \%$ of the agricultural production costs. Mechanized sugarcane harvesting presents some inconveniences, such as an increase in the amounts of foreign materials in the raw material, leading to a reduction in the quality of the harvested product, in addition to the stalks and fragments left in the field, characterized as losses resulting from the harvest.

Silva \& Garcia (2009) reported that the main factors related to harvest losses are the crop variety, management practices, soil and area preparation, harvester maintenance, operator skill, crop size, among others. Thus, the levels of losses may increase greatly if these factors are not properly monitored.
Companies of the sugar-energy sector have monitored the losses resulting from the mechanized sugarcane harvesting through field surveys, which allow calculating the arithmetic means of the quantified values. However, the analysis and identification of factors that aim to propose measures to reduce the level of losses are not always carried out. The combination of quantitative surveys and adequate tools for analyzing the monitoring of losses allows the detection of changes in the quality standards determined for the process and hence a faster resolution for the limiting factors (Silva et al., 2008).

In this sense, some authors have used statistical process control tools, such as individual value and moving average control charts, to identify the special causes that lead to instability, increasing the process variability (Voltarelli et al., 2015; Reis et al., 2015; Santana et al., 2015; Cassia et al., 2014, Voltarelli et al., 2015, Suryawanshi et al., 2013, Shin et al., 2012; Noronha et al., 2011). In all these studies, the statistical process control was effective in quantifying and monitoring the mechanized agricultural processes, which can show the

\footnotetext{
${ }^{2}$ Universidade Federal de São Carlos - Campus Lagoa do Sino/ Buri - SP, Brasil.

${ }^{3}$ Universidade Estadual Paulista - UNESP/ FCAV/ Jaboticabal - SP, Brasil.
} 
improvements that can be applied to the mechanized sugarcane harvesting, aiming at reducing the number of stalks left in the field.

Considering that the losses in the mechanized sugarcane harvesting present a high variability throughout the growing season in all harvest fronts, this study aimed to monitor these losses through the statistical process control.

\section{MATERIAL AND METHODS}

This study was carried out in an agricultural area of a sugarcane mill located in the region of Ribeirão Preto, SP, Brazil. The agricultural areas of this industrial unit present have a predominance of soils with flat and slightly wavy topography, with medium to clay textures. The regional climate is Cwa (humid subtropical), according to the Köppen classification.

The loss data of the entire 2012/13 growing season were used in this study, which was carried out from April to December 2012. The logistical division of harvesting machines was named work fronts. Each front consisted of a mean of eight harvesters, totaling 40 harvesters, and several tractor-wagon sets. Table 1 shows the model, year of manufacture, presence of the automatic base cutter system (auto tracker), and the mean gross effective harvesting capacity per harvester in the five fronts. The overall mean working speed of these harvesters for the fronts F1, F2, F3, F4, and F5 was approximately 5.0, 4.9, $5.2,5.1$, and $5.0 \mathrm{~km} \mathrm{~h}^{-1}$, respectively.

TABELA 1. Information of the harvesters used in the work fronts.

\begin{tabular}{cccccc}
\hline Front & Model & Year of manufacture $^{\mathbf{1}}$ & Auto tracker $^{\mathbf{2}}$ & Production/Harvester $^{\mathbf{3}}$ & Machine operator experience $^{\mathbf{4}}$ \\
\hline F1 & A-8800 & $2009 / 2010$ & Present & 44.54 & 3 years \\
F2 & A-7700 & 2007 & Present & 43.94 & 3 years \\
F3 & A-8800 & $2010 / 2011$ & Present & 44.98 & 4 years \\
F4 & A-7700 & 2007 & Present & 45.43 & 6 years \\
F5 & A-7700 & 2007 & Absent & 42.52 & Fill-in employees $^{*}$ \\
\hline
\end{tabular}

${ }^{1} \mathrm{~F} 1$ and $\mathrm{F} 3$ have machines from different years of manufacture. ${ }^{2}$ Device that automatically controls the height of the base cut. ${ }^{3} \mathrm{Mean}$ harvest capacity of harvesters $\left(\mathrm{t} \mathrm{h}^{-1}\right)$, calculated based on the Ripoli (1996) methodology. ${ }^{4}$ Mean time in years of experience of harvester operators. *Fill-in employees: they are not harvester operators, but act as such to replace another person.

The experimental design was completely randomized, based on the methodology of statistical process control (Montgomery, 2009), with part of the samples collected during the night time and the other part during the daytime. Ten samples were collected per day (five for the daytime shift and five for the nighttime shift), totaling 70 sample points in the week. The monitoring occurred until the end of the growing season, completing 50 weeks of evaluation. The harvester chosen for sampling losses was defined daily by the Production Unit (harvest coordinator), and this monitoring pattern is related to the crop management plan.

The quality indicators of the mechanized sugarcane harvesting were determined by the visible losses, which were collected using a frame with a sample area of $10 \mathrm{~m}^{2}$ $(3.00 \times 3.33 \mathrm{~m})$. Subsequently, the samples were separated, weighed, and quantified according to Silva et al. (2008) and adapted by the Production Unit, which classified the visible losses into stump (sugarcane fixed to the ground, with a length from 3 to $15 \mathrm{~cm}$ ), fixed piece (sugarcane piece fixed to the ground, longer than $16 \mathrm{~cm}$ and shorter than half the sugarcane size) + loose piece (sugarcane piece loose on the soil, not exceeding more than $50 \%$ of the stem size), fragment (sugarcane piece lower than or equal to $1 / 3$ the diameter of the billet, resulting from the impact with the exhaust fan propellers, whole sugarcane (sugarcane not collected by the harvester, fixed or not to the ground, longer than half the size of the stalk being harvested, and total losses (the sum of all losses previously described).

The collection and quantification of the types of losses in the mechanized sugarcane harvesting were carried out by quality audit teams with two members each of the Production Unit (work fronts). The members of all teams received training before the data collection to minimize experimental variations and maintain the quality standard required by the Production Unit. The collections to measure losses during the nighttime period were carried out before the start of the morning shift to avoid any experimental errors, while the collections to represent the daytime period were performed after the beginning of the morning shift.

The statistical analyses were performed using descriptive statistics to verify the behavior of the data set by measures of position (mean and median) and dispersion (coefficient of variation) and the coefficients of skewness and kurtosis. The Ryan-Joiner test was used to verify the normality of data distribution.

The coefficient of skewness (Cs) indicates the deviation of the variable from a central value, characterizing how and how much the frequency distribution deviates from the symmetry. The $\mathrm{Cs}>0$ represents a right-skewed distribution, $\mathrm{Cs}<0$ represents a left-skewed distribution, and $\mathrm{Cs}=0$ represents a symmetric distribution. The coefficient of kurtosis $(\mathrm{Ck})$ measures the degree of flatness of a distribution, that is, how flat a frequency curve will be relative to a normal reference curve. The $\mathrm{Ck}=0$ represents a mesokurtic (normal) distribution, $\quad \mathrm{Ck}<0$ represents a platykurtic (flat) distribution, and $\mathrm{Ck}>0$ represents a leptokurtic (elongated) distribution (Montgomery, 2009). On the other hand, the coefficient of variation was determined according to the methodology proposed by Pimentel-Gomes \& Garcia (2002), being classified as low $(<10 \%)$, medium (11 to $20 \%$ ), high ( 21 to $30 \%)$, and very high ( $>30 \%)$.

The analysis of the statistical process control of harvest was carried out using control charts through the previously described quality indicators. The control chart 
model selected for analysis of this study was the subgroup Xbar-S, which generates a control chart for the means of subgroups of all harvest fronts (Montgomery, 2009). The mean value of ten samples of losses was used for each weekday, totaling 70 sample points per week, for the elaboration of weekly control charts.

The control charts used had three lines. The central line represents the overall mean, and the other two lines represent the upper (UCL) and lower control limits (LCL), calculated based on the standard deviation of the variables, i.e., for UCL, the mean of the subgroup plus three times the standard deviation, and for LIC, the mean of the subgroup minus three times the standard deviation, when higher than zero. The stable process represents all sample points within the upper and lower control limits. The process is called unstable if the sampling points are out of both control limits and can be explained by the $6 \mathrm{M}$ factors (manpower, machinery, materials, methods, measurement, and mother-nature), seeking to eliminate the causes responsible for this variation (Montgomery, 2009).

According to Voltarelli et al. (2015), the general use of control charts is to detect possible variations external to the process, force the operation management by creating an improvement plan, and infer the capacity and limits established for the process.

\section{RESULTS AND DISCUSSION}

The results of total losses (Table 2) of the fronts F1, $\mathrm{F} 2$, and F3 were similar, with values between 2.7 and $3.0 \mathrm{t}$ $\mathrm{ha}^{-1}$, while the front F4 presented the lowest mean of total losses $\left(2.3 \mathrm{t} \mathrm{ha}^{-1}\right)$ and the front $\mathrm{F} 5$ showed the highest mean of total losses $\left(3.9 \mathrm{t} \mathrm{ha}^{-1}\right)$. These results can be directly related to the level of quality performed by each machine in each harvest front, being dependent on factors related to labor, environment, sampling methods, type of measurement, raw material, and the harvester constituents.

TABELA 2. Descriptive statistical analysis for losses in the mechanized sugarcane harvesting per work front.

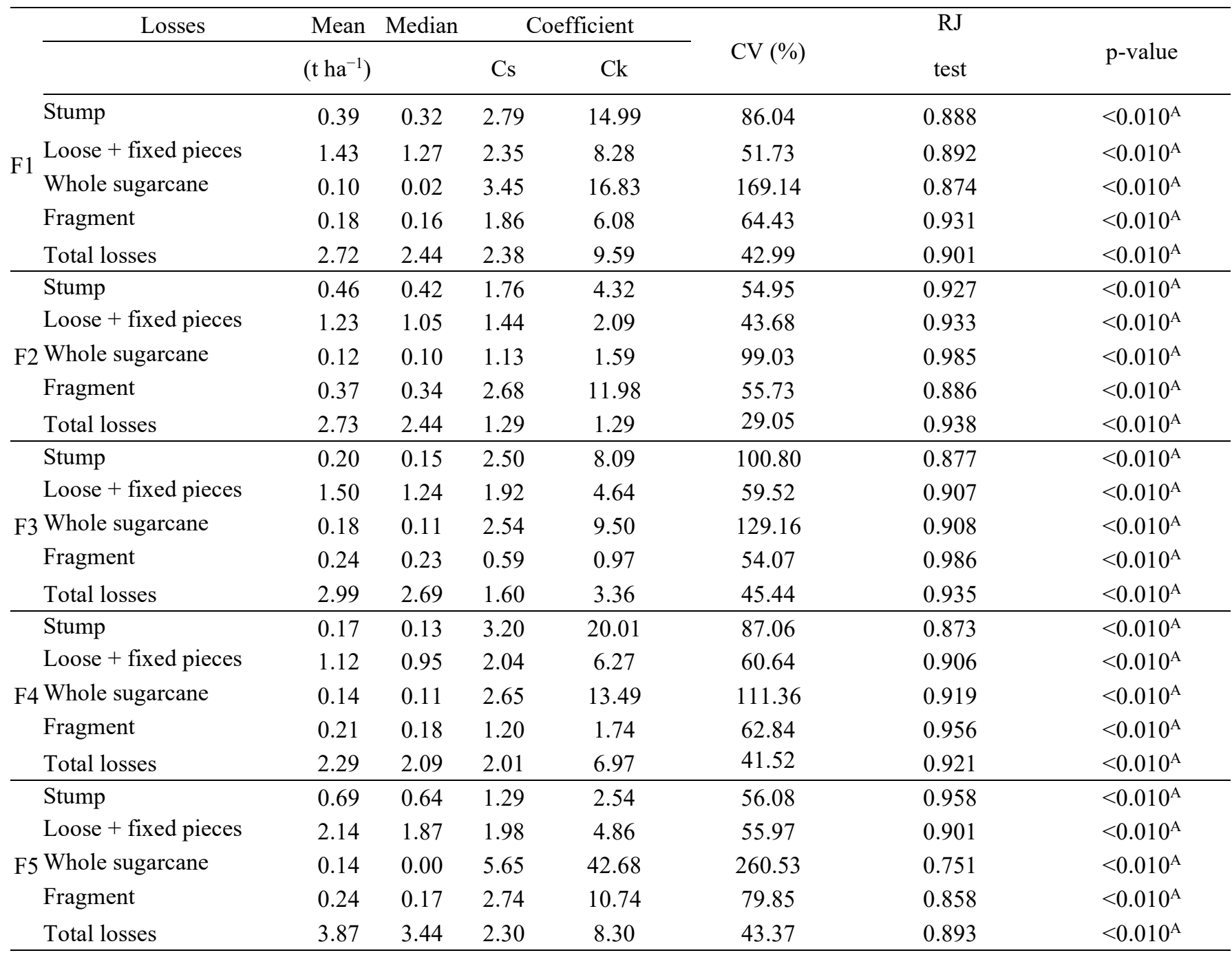

F1, F2, F3, F4, and F5: work fronts; Cs: coefficient of skewness; Ck: coefficient of kurtosis; CV: coefficient of variation; RJ: Ryan-Joiner normality test. *A: non-normal distribution; N: normal distribution.

The type of loss fixed and loose pieces was predominant because this modality has the longest stalk segments, thus representing the highest amount in the total lost mass, which can be explained by the absence of the automatic base cutter system. Voltarelli et al. (2015) studied loose piece losses in the mechanized sugarcane harvest and found values of approximately $0.140 \mathrm{t} \mathrm{ha}^{-1}$, which is different from the mean values found in the present study.

According to Silva et al. (2008), these losses 
usually occur in uneven terrains, with increased working speed, loss of machine control by the operator, deviating it from the row to be harvested, or changing the cutting height during the process, especially when working without the use of the auto tracker device. Harvesters have this automatic device, but its operation can be interrupted during the harvest process due to damages.

The descriptive statistics indicated that, in general, the studied losses had mean results close to the medians, but with higher values, represented by the positive coefficient of skewness. On the other hand, the coefficient of kurtosis showed leptokurtic curves, i.e., thinner than the normal curve, with extreme values and above the sample mean. All coefficients of variation were higher than $30 \%$, i.e., they are extremely high for all types of losses in the five harvest fronts, except for the results of the total loss of the front F2 $(\mathrm{CV}=29.05 \%)$, reflecting in high variability of the data set as a function of the surveys carried out during the growing season. Similarly, Silva et al. (2008) reported high variability in the loss sampling in mechanized sugarcane harvesting.

The behavior of the measures of central tendency and dispersion indicated the non-normality of the data set through its probability distribution curves for all types of losses and harvest fronts, which was evidenced by the Ryan-Joiner test, with high values and distant from zero. Voltarelli et al. (2015) monitored losses in the mechanized sugarcane harvesting using individual value, moving average, and exponentially weighted moving average control charts and reported that the normality of the data set, although desirable, is not essential for the application of statistical process control techniques and decision making during the process, once the process analyst has full knowledge of them and knows how to extract information necessary to improve the operation quality.

The type of loss stump showed process instability for the work fronts F1, F3, and F5 (Figure 1), demonstrated by the occurrence of subgroup means above the upper control limit. The fronts F2 and F4 showed less variability in the subgroup means, with a smaller interval between the upper and lower control limits. Stump losses (stalks left in the soil attached to the root with up to 15 $\mathrm{cm}$ ) are one of the main losses of sugar and/or ethanol in the industrial production, as the stalks left in the field have the highest sucrose concentration in the plant (Salvi et al., 2007).

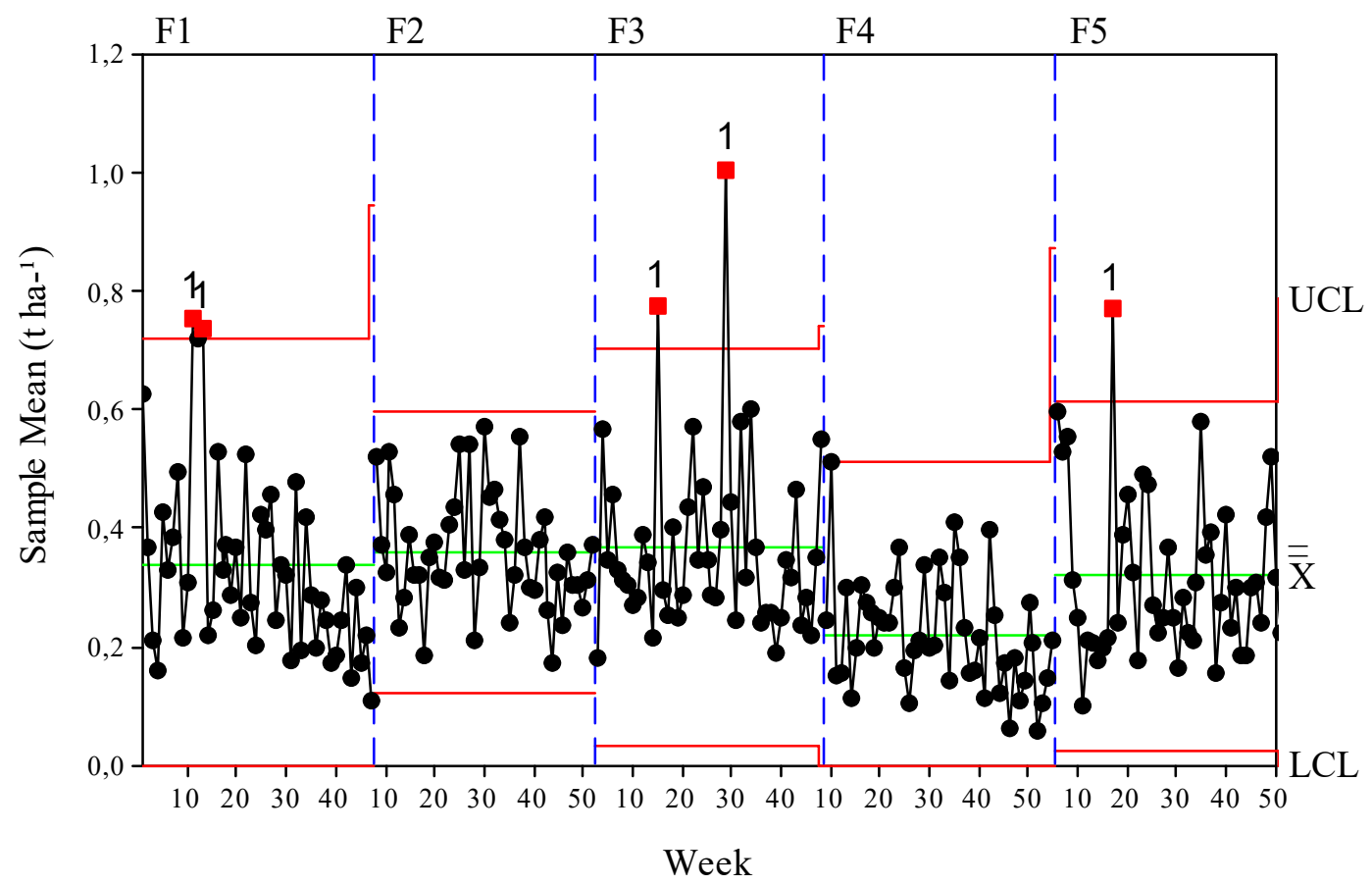

FIGURA 1. Xbar-S control chart for the type of loss stump considering the fronts F1, F2, F3, F4, and F5.

Points above the upper control limit during the beginning/middle of the growing season (fronts F3 and F5) can be attributed to the terrain unevenness, inefficient control of the base cut height, and incidence of stones in the harvested areas, which affect the cutting height. According to Salvi et al. (2007), the probable causes for the type of loss stump would be the non-operation of the floating box for base cutting, areas with stones, terrain leveling, and size of the sugarcane field, situations similar to what occurred for the present study. The high data variability in the front F5 can also be related to the little experience of operators and the lack of automatic control of the cutting height, as this front was constituted by the youngest operators, which could affect the operation quality until the man-machine relationship can be carried out effectively.

The type of loss fixed piece + loose piece (Figure 2) was out of the control limits of all fronts and mostly occur when the stalks were cut in the base inefficiently and failed to be directed towards the inside of the harvester by the feed roller to be processed. 


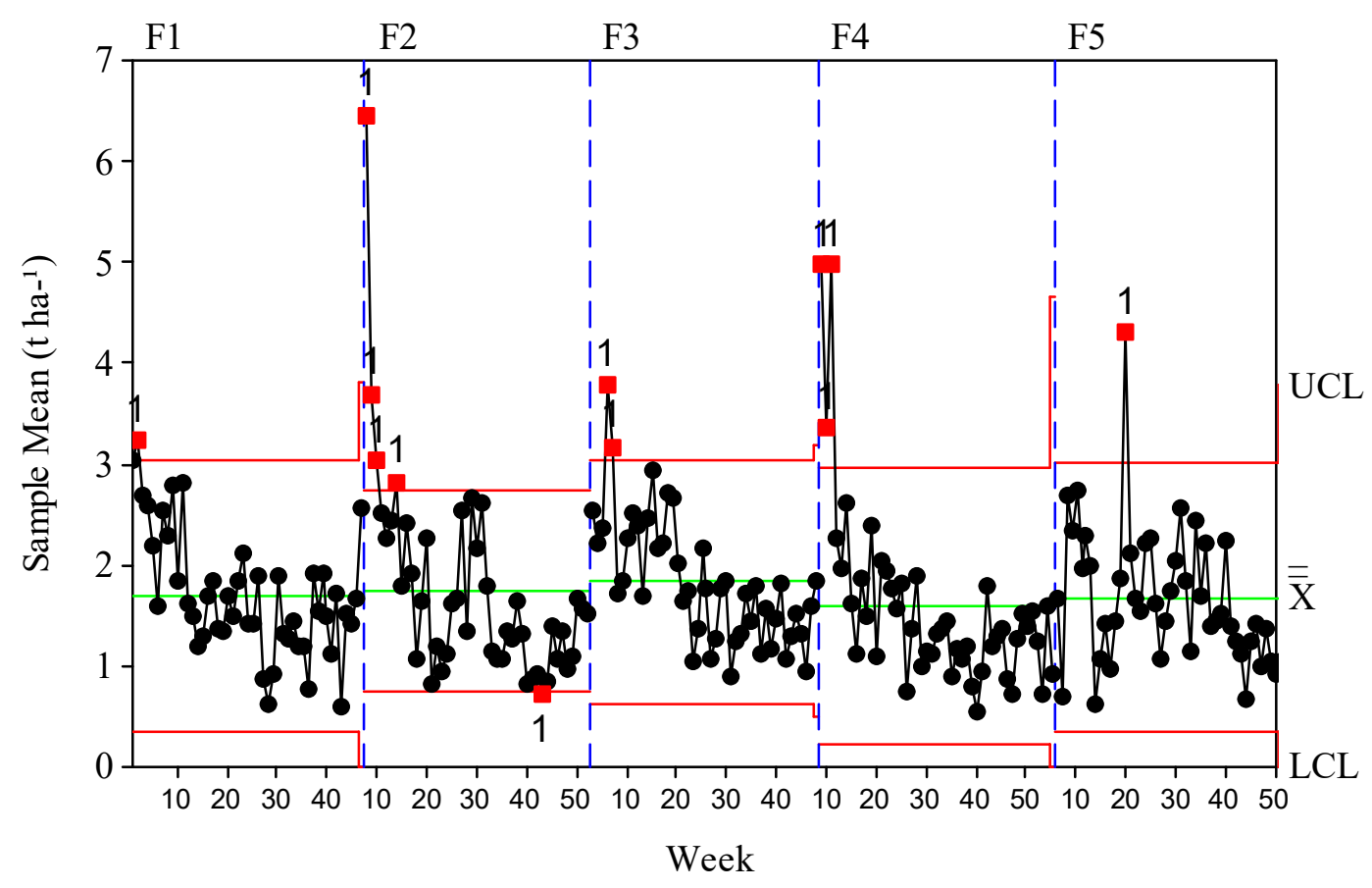

FIGURA 2. Xbar-S control chart for the type of loss fixed piece + loose piece considering the fronts F1, F2, F3, F4, and F5.

This type of loss is usually associated with the operator skills, high harvester speeds, uneven terrain, rechopping of stalks attached to the ground by the base cutter system, and lodged sugarcane plants, which are usually found in high-productivity fields or due to the wind action.

The control chart for the type of loss whole sugarcane (Figure 3) showed points that exceed the upper control limit in all harvest fronts. It occurred because this type of loss results mainly from the factors raw material (variety) and environment (wind). In this case, the points above the upper control limit occurred in samples from the lodged sugarcane field, as the methodology described by Ripoli (1996). Losses of whole sugarcane may be related to the lodging of sugarcane plants, which is usually related to the wind action, variety characteristics, or high productivity of the sugarcane field, making the harvester lifter roller and the collection mechanism ineffective after stalks being cut at the base.

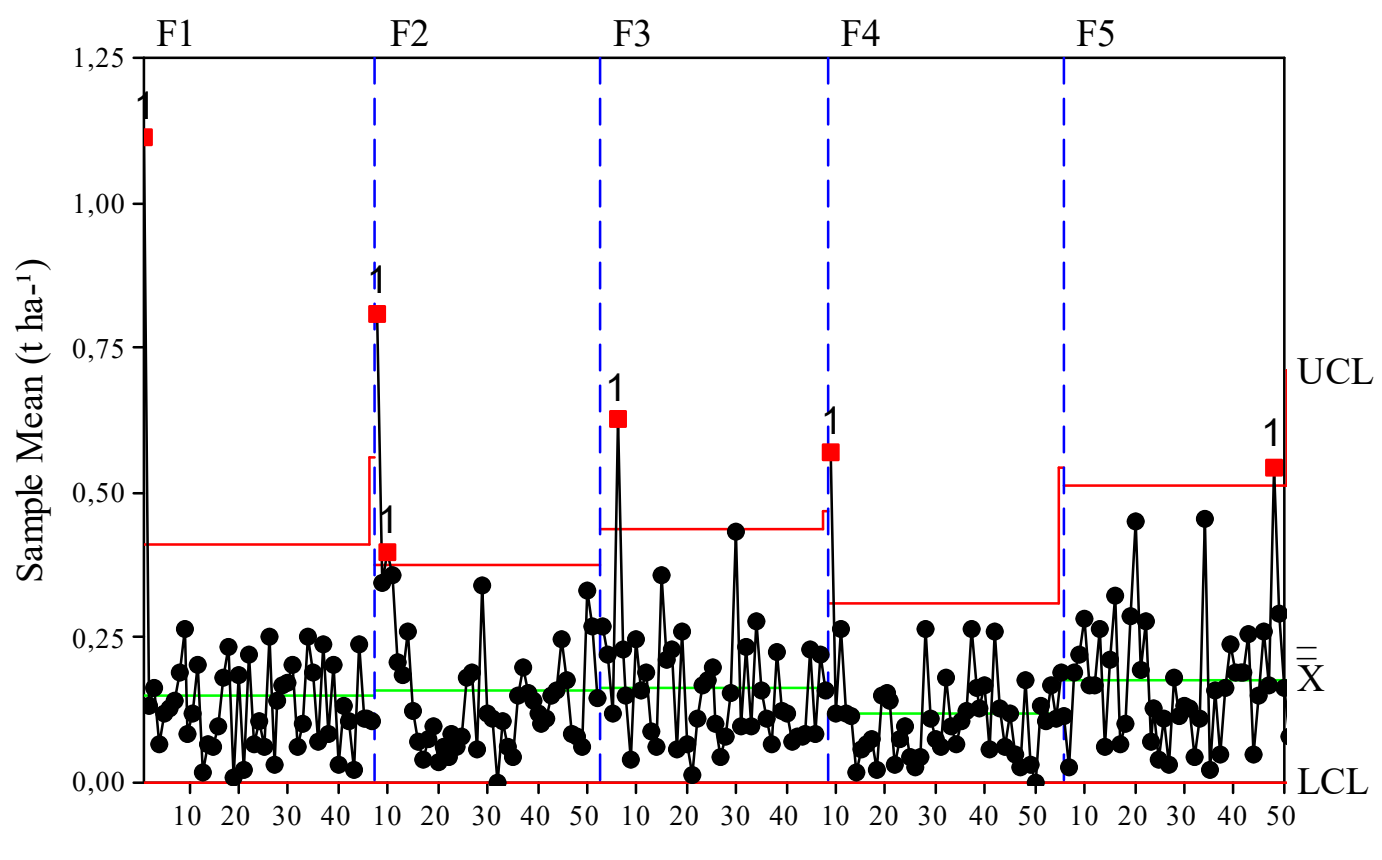

Week

FIGURA 3. Xbar-S control chart for type of loss whole sugarcane considering the fronts F1, F2, F3, F4, and F5. 
Moontree et al. (2012) evaluated losses in the mechanized sugarcane harvesting and reported the lowest values of whole sugarcane losses under the lowest harvester speed and during the correct machine alignment on the rows to be harvested, being also influenced by the inefficiency of sugarcane collection by the harvester platform. Similar results were also observed in some moments in the present study during the mechanized sugarcane harvesting, which can be evidenced by the points above the upper control limit.

The control charts for the type of loss fragment (Figure 4) showed a process considered unstable since some points exceeded the control limits in the five harvest fronts. Silva et al. (2008) observed similar results for this category of loss. The harvest fronts F1 and F3 presented points out of the upper control limit in the first three weeks of work. However, the process tended to be more homogeneous (fewer losses) after the third week, which is possibly due to the type of sugarcane field harvested in the first weeks, represented by lighter stalks and, consequently, lighter billets, which can be sucked and fragmented by the vacuum generated by the propellers of the primary extractor.

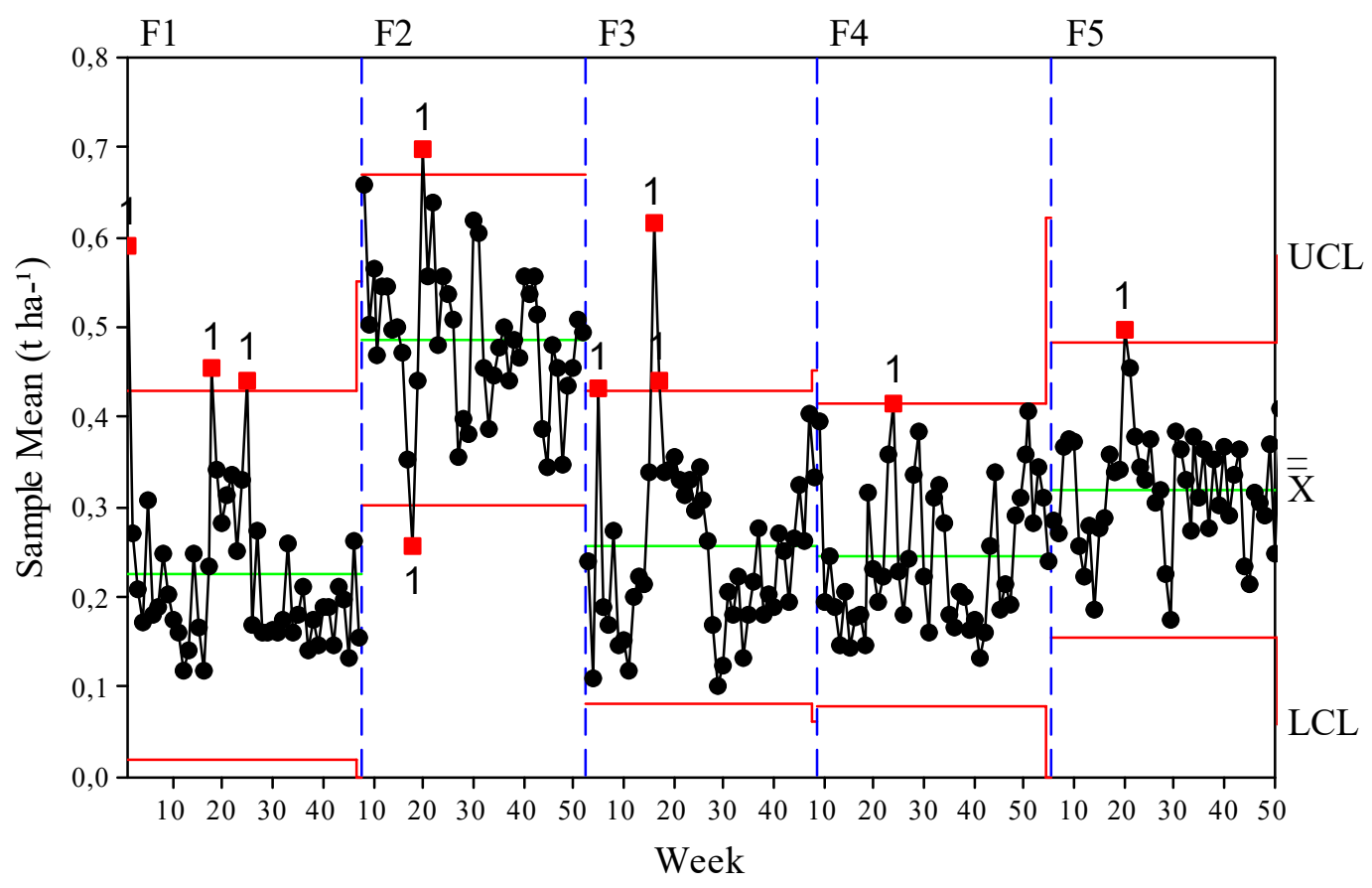

FIGURA 4. Xbar-S control chart for type of loss fragment considering the fronts F1, F2, F3, F4, and F5.

Another possible cause would be the speed regulation of the primary extractor, which could be above the recommended, being later regulated to decrease the loss rates for fragments. It illustrates the importance of monitoring losses using control charts since more effective decisions can be made when a possible abrupt variation or even a grouping or trend of loss values is observed, aiming at the process stability to achieve lower levels of losses. Manhães et al. (2014) evaluated the mechanized sugarcane harvesting at different working speeds and reported that the type of loss fragment presented no differences due to this factor, but their values were close to that found in the present study.
The quality indicator total losses in the mechanized sugarcane harvesting, which represents the sum of the other types of losses, presented a process considered unstable for all harvest fronts (Figure 5). The points out of the upper control limit occurred during the first harvest months for all harvest fronts. Despite being conceptually out of control, the mechanized sugarcane harvesting process can be considered an operation that can be controlled because part of the harvesters was not yet totally regulated in these periods, which may be explained by the non-compliance with the harvest planning, and the operators were still under adaption to the harvesters (higher man-machine efficiency during the mechanized sugarcane harvesting process). 




FIGURA 5. Xbar-S control chart for total losses considering the fronts F1, F2, F3, F4, and F5.

The overall mean of the front F5 was 12.87\% higher than the overall mean of the front F4, which registered the lowest loss rate. It suggests the great influence of the operator in the loss process since the front F5 was composed of operators with less experience. However, the harvest fronts had harvesters with different years of manufacture and, consequently, the absence and/or inefficiency of the automatic base cutter system, working speed, oscillation conditions due to the terrain micro-relief, sugarcane field size, among others, may have reflected in higher losses.

Voltarelli et al. (2015) monitored losses during the mechanized sugarcane harvesting throughout the growing season and reported that the mean total losses of the operation were approximately $2.0 \mathrm{t} \mathrm{ha}^{-1}$, a situation in which the process was also unstable. These results are lower than the mean value of losses found in the present study, which presented harvest losses of approximately 3.0 $\mathrm{tha}^{-1}$, showing a lower quality level during the operation.

\section{CONCLUSIONS}

The total losses showed higher and lower losses for the fronts F5 and F4, respectively, than the others.

Losses of loose and fixed pieces were higher than losses such as stump, whole sugarcane, and fragment for all work fronts.

The lowest variability of the mechanized sugarcane harvesting process was found for the type of losses stump, fixed and loose pieces, and total losses for the harvest front F2.

\section{REFERENCES}

Cassia MT, Silva RP, Paixão CSS, Bertonha RS, Cavichioli FA (2014) Desgaste das facas do corte basal na qualidade da colheita mecanizada de cana-de-açúcar. Ciência Rural 44(6):987-993.
Manhães CMC, Garcia RF, Correa Junior D, Francelino FMA, Francelino HO, Santos CMG (2014) Evaluation of visible losses and damage to the ratoon cane in the mechanized harvesting of sugarcane for diferent displacement speeds. American Journal of Plant Sciences 5(20):2956-2964.

Montgomery DC (2009) Control charts for variables. In: Montgomery DC. Introduction to statistical quality control, Wiley, $6^{\text {th }}$ ed. p 226-268.

Moontree T, Rittidech S, Bubphachot B (2012) Development of the sugarcane harvester using a small engine northeast Thailand. International Journal of Physical Sciences 7(44):5910-5917.

Noronha RHF, Silva RP, Chioderoli CA, Santos EP, Cassia MT (2011) Controle estatístico aplicado ao processo de colheita mecanizada diurna e noturna de canade-açúcar. Engenharia Agrícola 70(4):931-938.

Oliveira TBA, Selig PM, Barbosa VM, Campos LMDS, Bornia AC, Oliveira MWD (2012) Tecnologia e custos de produção de cana-de-açúcar: um estudo de caso em uma propriedade agrícola. Latin American Journal of Business Management 3(1):150-172.

Pimentel-Gomes F, Garcia CH (2002) Estatística aplicada a experimentos agronômicos e florestais: exposição com exemplos e orientações para uso de aplicativos. Piracicaba, FEALQ, 309p.

Reis GN, Voltarelli MA, Silva RP, Toledo A, Lopes A (2015) Qualidade do corte basal na colheita mecanizada de cana-de-açúcar em dois tipos de manejo do solo.

Comunicata Scientiae 6(2):143-153. 
Ripoli TCC (1996) Ensaio \& certificação de máquinas para colheita de cana-de-açúcar. In: Mialhe LG. Máquinas agrícolas: ensaios \& certificação. Piracicaba, Fundação de Estudos “Luiz de Queiroz”, p 635-73.

Salvi JV, Matos MA, Milan M (2007) Avaliação do desempenho de dispositivo de cortes de base de colhedora de cana-de-açúcar. Engenharia Agrícola 27(1):201-209.

Santana ATO, Voltarelli MA, Paixão CSS, Gírio LAS, Zerbato, C, Silva RP (2015) Características agronômicas da soja em semeadura convencional e cruzada. Revista Agro@mbiente 9(4):414-422.

Shin CS, Kim UK, Kim KW (2012) Energy efficiency classification of agricultural tractors in Korea. Journal of Biosystems Engineering 37(4):215-224.
Silva FIC, Garcia A (2009) Colheita mecânica e manual da cana-de-açúcar: Histórico e análise. Nucleus 6(1):233-248.

Silva RP, Correa CF, Cortez JW, Furlani CEA (2008) Controle estatístico aplicado ao processo de colheita mecanizada de cana-de-açúcar. Engenharia Agrícola 28(2):292-304.

Suryawanshi V, Thakur SS, Sharma S (2013) Performance evaluation of self-propelled sugarcane harvester. Journal of Sugarcane Research 3(1):35-40.

Voltarelli MA, Silva RP, Zerbato C, Paixão CSS, Tavares TO (2015) Monitoring of mechanical sugarcane harvesting through control charts. Engenharia Agrícola 35(6):1079-1092. 